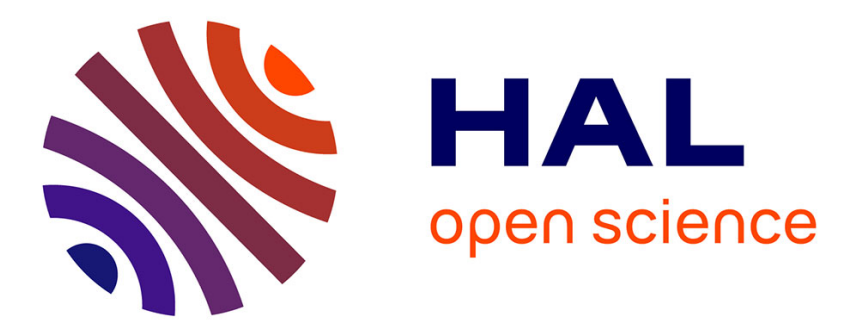

\title{
Decline in Fast Gait Speed as a Predictor of Disability in Older Adults
}

Fanny Artaud, Archana Singh-Manoux, Aline Dugravot, Christophe Tzourio, Alexis Elbaz

\section{- To cite this version:}

Fanny Artaud, Archana Singh-Manoux, Aline Dugravot, Christophe Tzourio, Alexis Elbaz. Decline in Fast Gait Speed as a Predictor of Disability in Older Adults. Journal of the American Geriatrics Society, 2015, 63 (6), pp.1129-1136. 10.1111/jgs.13442 . hal-02491090

\section{HAL Id: hal-02491090 https://hal.science/hal-02491090}

Submitted on 25 Feb 2020

HAL is a multi-disciplinary open access archive for the deposit and dissemination of scientific research documents, whether they are published or not. The documents may come from teaching and research institutions in France or abroad, or from public or private research centers.
L'archive ouverte pluridisciplinaire $\mathbf{H A L}$, est destinée au dépôt et à la diffusion de documents scientifiques de niveau recherche, publiés ou non, émanant des établissements d'enseignement et de recherche français ou étrangers, des laboratoires publics ou privés. 
Article type : Clinical Investigation

\section{Decline in Fast Gait Speed As a Predictor of Disability in Older Adults}

Fanny Artaud, MSc, PhD Candidate ${ }^{\mathrm{a}, \mathrm{b}}$ Archana Singh-Manoux, $\mathrm{PhD},{ }^{\mathrm{a}, \mathrm{b}, \mathrm{c}}$ Aline Dugravot, MSc, ${ }^{\mathrm{a}, \mathrm{b}}$ Christophe Tzourio, MD, $\mathrm{PhD},{ }^{\mathrm{d}, \mathrm{e}}$ and Alexis Elbaz, $\mathrm{MD}, \mathrm{PhD}^{\mathrm{a}, \mathrm{b}}$

${ }^{\mathrm{a} I N S E R M, ~ C e n t r e ~ f o r ~ R e s e a r c h ~ i n ~ E p i d e m i o l o g y ~ a n d ~ P o p u l a t i o n ~ H e a l t h, ~ U 1018, ~}$

Epidemiology of aging and age related diseases, Villejuif, France

${ }^{\mathrm{b}}$ University Versailles St-Quentin, UMRS 1018, Versailles, France

${ }^{c}$ Department of Epidemiology and Public Health, University College London, London, United Kingdom

${ }^{\mathrm{d}}$ INSERM U897, Neuroepidemiology Team, Bordeaux, France

${ }^{\mathrm{e}}$ University of Bordeaux, Bordeaux, France

Corresponding Author: Alexis Elbaz, INSERM, U1018, CESP Centre for Research in Epidemiology and Population Health, F-94807, Villejuif, France. E-mail:

alexis.elbaz@inserm.fr

Running head: Decline in gait speed predicts disability 


\section{ABSTRACT}

Objectives: To determine whether fast gait speed at study baseline and change in gate speed had independent associations with disability onset.

Design: Cohort study with 11-year follow-up (1999-2010).

Setting: Three-City Study, Dijon center, France.

Participants: Community-dwelling individuals aged 65 to 85 ( $\mathrm{N}=3,814,61 \%$ female).

Measurements: Fast gait speed (6 m) was assessed up to five times and disability (mobility (Rosow-Breslau scale), instrumental activities of daily living (IADLs; Lawton-Brody scale), basic activities of daily living (ADLs; Katz scale)) six times. A hierarchical disability indicator was constructed; participants were considered disabled if they reported difficulties with mobility and IADLs or with mobility, IADLs, and ADLs. The association between baseline fast gait speed and its slope of change and disability incidence was examined using joint models for longitudinal and time-to-event data.

Results: Over follow-up, 628 participants (68\% women) developed disability. Mean fast gait speed at baseline was $1.54 \mathrm{~m} / \mathrm{s}$, and annual decline was approximately $0.017 \mathrm{~m} / \mathrm{s}$. The hazard ratio of disability per standard deviation $(\mathrm{SD})(-0.22 \mathrm{~m} / \mathrm{s})$ slower baseline fast gait speed was $1.77(95 \%$ confidence interval $(\mathrm{CI})=1.60-1.94)$ and for one-SD $(-0.013 \mathrm{~m} / \mathrm{s})$ faster annual decline was $1.38(95 \% \mathrm{CI}=1.10-1.73)$ when both parameters were included in a sex- and ageadjusted model. All associations remained statistically significant in multivariable models, except for slope of change when chronic conditions were added to the model; of chronic conditions, dyspnea was the main contributor.

Conclusion: Accelerated decline in fast gait speed was associated with disability independent of baseline fast gait speed. These results underline the interest of measuring gait speed repeatedly and the need to identify determinants of decline, because they are likely to be targets for prevention and treatment to reduce disability risk. Key words: aged, cohort study, disability, epidemiology, motor decline. 
Given increasing life expectancy, the burden of disability is expected to rise. Disability is associated with risk of hospitalization, institutionalization, and death. ${ }^{1-3}$ Identifying persons at risk of disability before they become disabled may allow high-risk populations to be identified and preventive strategies to be implemented. ${ }^{4}$

Previous research has shown that slow gait speed is a robust predictor of onset of disability, ${ }^{5-8}$ but the majority of these studies used a single measure of gait speed to predict subsequent disability. There are two shortcomings with this approach. One, a single assessment might simply reflect low vitality and poor general health. If so, attempts to improve gait speed are unlikely to reduce risk of disability. Two, measurement error is more likely to bias findings from studies that use single assessments. Decline in gait speed has been shown to be associated with mortality, ${ }^{9-11}$ but few studies have examined its association with disability, with inconsistent findings. ${ }^{12-15}$

Whether baseline fast gait speed and change in fast gait speed over follow-up were independently associated with incidence of disability over 11 years of follow-up was examined in a cohort of French community-dwelling older adults from the Dijon center of the Three-City (3C) Study.

\section{METHODS}

\section{Study population}

The 3C Study recruited community-dwelling individuals aged 65 and older from electoral rolls in three French cities in 1999-2001 (Bordeaux, Dijon, Montpellier). ${ }^{16}$

The present study is based on data from Dijon $(n=4,931)$, where a specific study on physical performance was undertaken on adults aged 65 to 85 . Participants younger than 85 were invited to the study center to be interviewed in person and for additional investigations at baseline and after 2 (Wave 1, 2001-02), 4 (Wave 2, 2003-04), 7 (Wave 4, 2006-07), 9 (Wave 5, 2008-09), and 11 (Wave 6, 2010-12) years. Older participants were seen at home; from 
Wave 2 onward, all participants were offered the opportunity of being seen at home. Wave 3 (2005-06) consisted only of a self-administered questionnaire.

The ethical committee of the Kremlin-Bicêtre University-Hospital (France) approved the study protocol, and all participants gave written informed consent.

\section{Gait speed}

Gait speed was measured in participants younger than 85 who visited the study center at baseline and Waves 2, 4, 5, and 6 using two photoelectric cells (6 m apart) connected to a chronometer. Participants were asked to walk at usual and fast (without running) speeds. They started walking $3 \mathrm{~m}$ before the start line and stopped walking after the end line so that the measure included neither acceleration nor deceleration time. At Wave 6, for participants younger than 85 who were seen at home, portable photoelectric cells (Racetime2 kit light radio, MicroGate) were used using the same protocol as at the study center. Gait speed was therefore measured at home over $6 \mathrm{~m}$ in most instances $(85 \%)$; shorter distances $(3.5-5.9 \mathrm{~m})$ were used if there was not enough space at home.

Gait speed $(\mathrm{m} / \mathrm{s})$ was computed as $6 \mathrm{~m}$ divided by the time taken to walk this distance (seconds). Short-term reproducibility was assessed using two measures 5 minutes apart in a random sample of 51 participants (mean age $80.1 \pm 3.4$ ). Intraclass correlation coefficients (standard errors (SEs)) were 0.84 (0.02) for usual speed and $0.92(0.02)$ for fast speed. ${ }^{17}$ Given greater annual decline $(-0.017 \mathrm{vs}-0.005 \mathrm{~m} / \mathrm{s})$, in agreement with other reports, ${ }^{18,19}$ and greater interindividual variability (random variability of the slope (SE) $0.0002(0.00002)$ vs $0.0001(0.00001))$ in fast speed than usual speed, fast speed was used in the analyses.

\section{Disability}

Three disability domains (supplementary methods) were assessed six times (baseline, Waves 1, 2, 4, 5, 6). Mobility was assessed using the French translation of the Rosow and Breslau scale, which evaluates the ability to perform heavy work around the house, walk half a mile, and climb stairs. ${ }^{20}$ The French version of the Lawton-Brody instrumental activity of daily 
living (IADL) scale evaluates the ability to use a telephone, manage drugs and money, use public or private transportation, and shop and, additionally for women, prepare meals and do housework and laundry. ${ }^{21}$ Basic activities of daily living (ADLs) were assessed using the French version of the Katz scale, which evaluates whether participants need help with bathing, dressing, toileting, transferring from bed to chair, and eating; incontinence was excluded because it reflects organ impairment rather than functional limitation. ${ }^{22}$ For each domain, participants were considered disabled if they could not perform at least one activity without a given level of help, as defined according to the respective instrument.

A hierarchical disability indicator was constructed ${ }^{23}$ that defines four levels of increasing disability by summing up responses to the three dichotomized disability items in a hierarchy ( $0=$ fully independent, $1=$ dependent only in relation to the Rosow scale, $2=$ dependent on the Rosow and IADL scales but not the ADL scale, $3=$ dependent in all domains). This approach has the advantage of taking three disability domains into account simultaneously; it has a reproducibility coefficient of 0.99 and a scalability coefficient of $0.98 .^{23,24}$ Few people were disabled in all three domains, leading to the creation of two groups: 2/3 (moderate/severe disability) and 0/1 (no/light disability).

\section{Covariates}

Sociodemographic measures drawn from study baseline included age, sex, education (no education to primary school, secondary school, high school to university), and marital status (married; divorced, separated, widowed; single). An unhealthy behaviors score was established as the number of unhealthy behaviors (range 0-4) using measures from study baseline: low to intermediate physical activity (walking $<1 \mathrm{~h} / \mathrm{d}$ and/or exercising $<1$ time/wk); consumption of fruits and vegetables less than once per day; current or recent exsmoker (quit smoking <15 years before baseline); never, former, or heavy drinker ( $>21$ alcoholic drinks/wk for men, $>14$ for women). ${ }^{25}$ 
Anthropometric measures included body mass index (BMI) and height. Weight was measured during clinical examinations or self-reported during interviews at all waves. Height was measured or self-reported at baseline and Wave 4. When both measures were available, clinical assessments were used. BMI $\left(\mathrm{kg} / \mathrm{m}^{2}\right)$ was calculated as weight divided by height squared; baseline height was used to compute BMI at baseline and Waves 1 and 2, and height from Wave 4 was used to compute BMI at Waves 4 to 6.

The following covariates were assessed at study baseline and at each wave of data collection. Cognition was assessed using the Mini-Mental State Examination (MMSE), with higher scores corresponding to better function. Depressive symptomatology were measured using the Center for Epidemiologic Studies Depression Scale (CES-D), with scores of 16 or greater corresponding to high depressive symptoms; ${ }^{26}$ use of psychotropic drugs (antidepressants, anxiolytics, benzodiazepines, hypnotics) was also recorded. Trauma included history of bone fracture or recurrent falls ( $\geq 2$ falls) over the 2 years preceding each visit. Chronic conditions included self-reported diabetes mellitus, Parkinson's disease, vision difficulties (difficulty recognizing familiar faces at a distance of $\leq 4 \mathrm{~m}$, with or without glasses), deafness, dyspnea (classes II, III, or IV of the New York Heart Association classification: breathless with minor effort, during ordinary activity, or at rest), regular use of nonsteroidal antiinflammatory drugs for joint pain, and knee or hip replacement for osteoarthritis. Cardiovascular disease and risk factors included stroke, coronary heart disease, lower-limb arteritis, hypertension (systolic blood pressure $\geq 140 \mathrm{mmHg}$, diastolic blood pressure $\geq 90 \mathrm{mmHg}$, or antihypertensive medication), and lipid-lowering drugs as a surrogate for hypercholesterolemia. Expert committees validated incident stroke and coronary heart disease events using hospital and other medical records. ${ }^{27}$

\section{Statistical analysis}

Individuals who were disabled at baseline or had missing data for any of the covariates, for whom disability status was unknown at all waves, or for whom fast gait speed was never 
measured during follow-up were excluded. Because fast gait speed was measured between age 65 and 85 only, follow-up for disability was restricted to that range. Disability was assessed at each wave, so its precise date of onset was unknown; the midpoint between the data collection wave at which the participant was deemed to have disability and the previous one was therefore used as the date of disability onset. Follow-up was until Wave 6 for participants who remained disability free and for whom fast gait speed was measured at that wave, date of onset of disability for participants in whom fast gait speed was assessed at the previous wave, and date of last assessment at which fast gait speed was measured for all other participants censored as nondisabled at that date.

Participant characteristics were described as a function of disability status at the end of follow-up. Change in fast gait speed was first examined as a function of disability status using a linear mixed model, including the intercept and slope as random effects and a backward scale for time (in years). In addition to an indicator of disability status at the end of follow-up and its interaction with time, the model was adjusted for age at the end of follow-up, sex, and the interaction between sex and time.

To examine the association between baseline fast gait speed and change in fast gait speed over time and the incidence of disability, a joint modeling approach was used that jointly estimates the parameters of longitudinal and survival submodels (supplementary methods). The intercept and slope (change over time) of the longitudinal submodel were treated as random effects, and sex and baseline age (centered at 65) and their interactions with time were treated as fixed effects. A Weibull function was used for the survival submodel, adjusted for sex and baseline age (centered at 65). Because the independent effects of baseline fast gait speed and change therein on the incidence of disability was of interest, the random intercept (corresponding to individual differences in baseline fast gait speed) and slope (corresponding to individual differences in the slope of change in fast gait speed) were included in the survival submodel to estimate hazard ratios (HRs). ${ }^{28,29}$ 
The role of covariates in explaining the association between fast gait speed and disability was assessed by including them in the survival submodel from the baseline assessment (sociodemographic measures, unhealthy behaviors, height) or as time-dependent variables (BMI, MMSE tertiles, depressive symptomatology, trauma, chronic conditions, cardiovascular disease, and risk factors). Models with covariates were compared with one without them; their contribution was estimated as percentage change in HRs as $100 \times\left(\log H R_{\text {Model1 }}-\log H R_{\text {Modeli }}\right) / \log H R_{\text {Model1 }}$.

To exclude reverse causation bias, participants who developed disability in the first 4 (Waves 1-2) and 7 years of follow-up (Waves 1-4) were excluded from sensitivity analyses. The main analyses did not take into account the possibility that some participants may recover from disability; the analysis were repeated by excluding participants who recovered from disability and remained disability free throughout the remaining follow-up. Analyses were performed using SAS 9.3 (SAS Institute, Inc., Cary, NC) and Stata 12.1 (stjm command; StataCorp LP, College Station, TX); P-values were two-sided and those $\leq .05$ were considered statistically significant.

\section{RESULTS}

At study baseline, $379(8.1 \%)$ of 4,692 individuals aged 65 to 85 were disabled and excluded from the analyses. After excluding individuals with missing data for covariates $(n=66)$, disability status ( $n=25)$, or fast gait speed (394 participants with missing measures at all waves and 60 with missing measures before they became disabled), the analyses were based on 3,814 participants. Excluded participants $(\mathrm{n}=499)$ were older $(76.2$ vs $73.2, \mathrm{P}<.001)$ and less educated (no education to primary school, $38.5 \%$ vs $33.8 \%$, age-adjusted $\mathrm{P}=.02$ ) than those included in the analyses.

During a total follow-up of 11 years (mean $5.1 \pm 4.2$ years), 3,814 participants contributed 20,338 person-years; 628 (68.0\% women) developed disability (incidence, 30.9/1,000 personyears). Table 1 shows that participants who developed disability were more likely to be 
female, to be married, to walk more slowly, and to be in worse health. In particular, there was a strong association between dyspnea and disability over follow-up (odds ratio $(\mathrm{OR})=2.23$, $\mathrm{P}<.001)$. Mean fast gait speed at baseline was $1.54 \pm 0.30 \mathrm{~m} / \mathrm{s}$. Older and less-educated participants, women, and those in worse health walked more slowly; dyspnea had the strongest effect (beta $=-11.65, \mathrm{P}<.001)$ (Supplementary Table 1).

In an unadjusted linear mixed model, mean annual decline in fast gait speed was $-0.017 \mathrm{~m} / \mathrm{s}$. Those who walked faster at baseline experienced somewhat greater decline over follow-up than those who walked more slowly (covariance of random intercept and slope $=-8.26$, $\mathrm{SE}=1.93, \mathrm{P}<.001$ ), although this effect was not strong, as evidenced in the spread of participants in the cross-tabulation of quartiles of the individual predictions (best linear unbiased prediction) of intercepts and slopes (Supplementary Table 2).

Figure 1 presents predicted trajectories of fast gait speed according to disability status at the end of follow-up for 75-year-old women (estimates in Supplementary Table 3). Those who developed disability during follow-up had a 20\% ( $\mathrm{p}<.001)$ faster annual decline in fast gait speed $(-0.024 \mathrm{~m} / \mathrm{s}, 95 \%$ confidence interval $(\mathrm{CI})=-0.028,-0.021)$ than those who remained disability free $(-0.020 \mathrm{~m} / \mathrm{s}, 95 \% \mathrm{CI}=-0.022,-0.019)$.

Table 2 shows the association between fast gait speed at baseline and change in fast gait speed and incidence of disability. In the simplest model (Model 0), the HR of disability per SD ($0.22 \mathrm{~m} / \mathrm{s}$ ) slower fast gait speed at baseline (random intercept) was 1.73 (95\% CI=1.57-1.90). In a model with the random intercept and slope (Model 1), the HR of disability per SD was $1.77(95 \% \mathrm{CI}=1.60-1.94)$ for slower fast gait speed at baseline and 1.38 (95\% $\mathrm{CI}=1.10-1.73)$ for $1-\mathrm{SD}(-0.013 \mathrm{~m} / \mathrm{s}$ per year) decrease in the random slope (representing faster decline in fast gait speed). For baseline fast gait speed, the association remained significant in the fully adjusted model $(\mathrm{HR}=1.54,95 \% \mathrm{CI}=1.39-1.72)$; covariates explained $23.6 \%$ of the association. The highest percentage reduction was for chronic conditions (10.4\%). For change in fast gait speed, the association became nonsignificant in the fully adjusted model 
$(\mathrm{HR}=1.05,95 \% \mathrm{CI}=0.83-1.32)$; covariates explained $86.3 \%$ of the association. The highest percentage reduction was for chronic conditions (58.9\%). Dyspnea was the chronic condition that played the strongest role, for baseline speed (6.6\%) and change (42.1\%).

Participants who developed disability during the first 4 to 7 years of follow-up were excluded from sensitivity analyses (Table 3). Baseline fast gait speed remained associated with disability, with HRs in the same range as in main analyses. The HR for change in fast gait speed was similar to that of main analyses when excluding the first 4 years and tended to be somewhat stronger when excluding the first 7 years. During follow-up, 178 participants recovered from disability and remained disability free throughout follow-up. Analyses excluding these participants showed associations that were even stronger than those from the main analyses (Supplementary Table 4).

\section{DISCUSSION}

Based on a large cohort of French community-dwelling older adults followed over 11 years, slower fast gait speed at baseline and faster decline in fast gait speed thereafter were independent predictors of incident disability. The strength of the association was stronger for fast gait speed at baseline, but HRs were similar to that associated with decline (1.4 to 1.8). Chronic conditions, especially dyspnea, explained the largest part of the associations. Finally, fast gait speed at baseline was associated with incident disability 7 years after, independent of change in fast gait speed over this period.

These findings extend those of previous studies showing that poor physical performance is associated with disability, ${ }^{5-8}$ although few studies have examined the role of change in physical performance. One study in Americans aged 65 and older showed that poor grip strength and slow gait speed 11 years after baseline and faster decline in grip strength and stride length 5 to 11 years after baseline independently predicted three domains of disability (mobility, upper-extremity function, ADLs) 18 years after baseline. ${ }^{14}$ Another study in Americans aged 72 and older examined the association between physical performance (gait 
speed, timed chair stands, speed of turning) and their change between baseline and Year 1 and ADL disability; ${ }^{12}$ decline in physical performance was associated with disability at Year 1 after adjusting for baseline performance but was not associated with disability at Year 3 after adjusting for physical performance at Year 1 . These contradictory results may result from the small interval used to determine change in performance and from the long interval between the last gait speed measure and the disability assessment for the second analysis. In addition, change was assessed based on two measures only, which may be subject to regression to the mean. Another study of 93 disabled women aged 65 and older assessed weekly over 24 weeks examined the short-term effect of change in physical function (summary score including gait speed, standing balance, rising from a chair) on ADLs and mobility. ${ }^{13}$ At each time point, baseline and change in physical performance were independently associated with disability. Finally, a study in Italians aged 65 and older reported that the latest assessed lower extremity performance is a strong predictor of incident mobility and ADL disability independent of previous performance. ${ }^{30}$ That study measured physical performance twice ( 3 years apart) and examined incident disability 6 and 9 years later, whereas the current study measured fast gait speed five times and disability six times over 11 years. The small interval between the two assessments of physical performance and the long interval between the first measure and the disability assessment may account for inconsistent findings.

Using up to five assessments to estimate change in fast gait speed over 11 years, it was shown that it predicted disability independent of fast gait speed at the start of the study. Therefore, assessment of change in fast gait speed, in addition to single assessments, allows the identification of persons whose fast gait speed is initially fine but experience faster decline over follow-up as being at risk of disability. Although those who walked faster tended to have a more-pronounced decline in fast gait speed over follow-up, the correlation was not strong, and participants were relatively evenly distributed across quartiles of initial fast gait speed and change in fast gait speed. 
Disability is a long-term process that results from the accumulation of deficits over time.

Thus, fast gait speed at study baseline may be a stronger predictor of disability occurring early during follow-up. This hypothesis was tested by excluding cases of disability arising in the 4 to 7 years after the start of the study, and it was found that baseline fast gait speed continued to predict disability at least 7 years later, independent of change in fast gait speed. Therefore, slower fast gait speed is an early marker of future disability and is present several years before disability onset.

The covariates played a stronger role in explaining the association between disability and change in fast gait speed than with baseline fast gait speed. Baseline covariates do not capture all of the lifecourse exposure history of participants before the baseline assessment, whereas changes in covariates over the study period are likely to better capture change in important confounders after the baseline assessment; therefore, it is likely that residual confounding is more important for the baseline association than for the association with change. Multiple factors are likely to be involved in the association between fast gait speed and disability. Dyspnea had the strongest association with fast gait speed and disability and the strongest role in explaining their association. Dyspnea may result from heart failure, chronic obstructive pulmonary disease, and obesity, all of which are risk factors for slow gait speed and disability. ${ }^{24,31}$ The results of the current study confirm that better prevention or management of chronic diseases may reduce the risk of disability.

These findings need to be considered in light of some limitations. First, joint models cannot accommodate the interval-censored nature of these data, requiring the use of the midpoint between the wave at which disability was reported and the previous wave to define the date of disability onset. Nevertheless, this approach is reasonable when intervals between assessments are not too large. ${ }^{32}$ Second, the possibility that some people may recover from disability was not taken into account, although analyses excluding these people did not change the conclusions. Third, fast rather than usual gait speed was used for the analyses, 
mainly raison because the former has a steeper decline and larger interindividual heterogeneity than the latter; these results therefore apply to this measure only. Although clinicians may use it less often than usual gait speed, fast gait speed has been implemented in many studies and settings and is simple to measure; the findings are in favor of its clinical value. Fourth, participants excluded from the analyses were older at baseline and less educated but not significantly different from other participants in terms of sex and marital status. Although the absolute risk of disability was probably underestimated, this would be unlikely to bias the estimate of the associations. Fifth, because fast gait speed was measured only between the ages of 65 and 85 , the findings cannot be generalized beyond this age range. This study's main strengths include its large size and long follow-up with up to six disability and five fast gait speed measures, allowing a precise estimate of fast gait speed decline to be obtained. Physical performance was assessed using an objective and highly reproducible measure. Joint models have several advantages over time-dependent Cox proportional hazard models. By modeling the longitudinal variable as a random process (fast gait speed), they allow more-precise examination of the association between the longitudinal process and outcome by taking measurement error into account. ${ }^{33}$ These models are remarkably flexible, whereas time-dependent Cox proportional hazards models allow only the association between the current value of the longitudinal process and the incidence of the outcome to be examined, not allowing the analysis of change in exposure.

In conclusion, in French older adults, slower fast gait speed at baseline was a robust predictor of disability, even assessed 7 years before disability. Moreover, change in fast gait speed was associated with disability onset over 11 years of follow-up, independent of initial fast gait speed. These results show the importance of repeated physical and disability assessments in older adults to better identify those at higher risk of becoming disabled.

\section{ACKNOWLEDGMENTS}


Conflict of Interest: The editor in chief has reviewed the conflict of interest checklist provided by the authors and has determined that the authors have no financial or any other kind of personal conflicts with this paper. Fanny Artaud is the recipient of a doctoral grant from the EHESP (Ecole des Hautes Etudes en Santé Publique), Rennes, France. Archana SinghManoux receives research support from the National Institutes of Health (National Institute on Aging R01AG013196 (PI), R01AG034454 (PI))

The 3C Study was supported by a partnership agreement between the Institut National de la Santé et de la Recherche Médicale (INSERM), the Victor Segalen-Bordeaux II University, and the Sanofi-Synthélabo Company. The Fondation pour la Recherche Médicale funded the preparation and initiation of the study. The 3C Study is also supported by the Caisse Nationale Maladie des Travailleurs Salariés, Direction Générale de la Santé, Conseils Régionaux of Bourgogne, Fondation de France, Ministry of Research-INSERM Program, “Cohortes et collections de données biologiques,” Mutuelle Générale de l’Education Nationale, Institut de la Longévité, Conseil Général de la Côte d'or, Fondation Plan Alzheimer.

Author Contributions: Artaud, Elbaz: study design and research. Artaud: data analysis. Dugravot: statistical analysis. Artaud, Singh-Manoux, Elbaz: writing of the paper. Tzourio, Elbaz: data acquisition. Artaud, Elbaz: primary responsibility for final content. All authors read and approved the final manuscript.

Sponsor's Role: None.

\section{REFERENCES}

1. Fried LP, Guralnik JM. Disability in older adults: Evidence regarding significance, etiology, and risk. J Am Geriatr Soc 1997;45:92-100.

2. Fried LP, Kronmal RA, Newman AB et al. Risk factors for 5-year mortality in older adults: The Cardiovascular Health Study. JAMA 1998;279:585-592. 
3. Gaugler JE, Duval S, Anderson KA et al. Predicting nursing home admission in the U.S: A meta-analysis. BMC Geriatr 2007;7:13.

4. Daniels R, Metzethin S, van Rossum E et al. Interventions to prevent disability in frail community-dwelling older persons: An overview. Eur J Ageing 2010;7:37-55.

5. Guralnik JM, Ferrucci L, Simonsick EM et al. Lower-extremity function in persons over the age of 70 years as a predictor of subsequent disability. N Engl J Med 1995;332:556561.

6. Guralnik JM, Ferrucci L, Pieper CF et al. Lower extremity function and subsequent disability: Consistency across studies, predictive models, and value of gait speed alone compared with the short physical performance battery. J Gerontol A Biol Sci Med Sci 2000;55A:M221-M231.

7. Rosano C, Newman AB, Katz R et al. Association between lower digit symbol substitution test score and slower gait and greater risk of mortality and of developing incident disability in well-functioning older adults. J Am Geriatr Soc 2008;56:1618-1625.

8. den Ouden ME, Schuurmans MJ, Arts IE et al. Physical performance characteristics related to disability in older persons: A systematic review. Maturitas 2011;69:208-219.

9. Perera S, Studenski S, Chandler JM et al. Magnitude and patterns of decline in health and function in 1 year affect subsequent 5-year survival. J Gerontol A Biol Sci Med Sci 2005;60A:894-900.

10. White DK, Neogi T, Nevitt MC et al. Trajectories of gait speed predict mortality in well-functioning older adults: The Health, Aging and Body Composition study. J Gerontol A Biol Sci Med Sci 2013;68A:456-464.

11. Sabia S, Dumurgier J, Tavernier B et al. Change in fast walking speed preceding death: Results from a prospective longitudinal cohort study. J Gerontol A Biol Sci Med Sci 2014;69A:354-362. 
12. Gill TM, Williams CS, Mendes de Leon CF et al. The role of change in physical performance in determining risk for dependence in activities of daily living among nondisabled community-living elderly persons. J Clin Epidemiol 1997;50:765-772.

13. Mendes de Leon CF, Guralnik JM, Bandeen-Roche K. Short-term change in physical function and disability: The Women's Health and Aging Study. J Gerontol B Psychol Sci Soc Sci 2002;57B:S355-S365.

14. Hirsch $\mathrm{CH}$, Buzkova P, Robbins JA et al. Predicting late-life disability and death by the rate of decline in physical performance measures. Age Ageing 2012;41:155-161.

15. McDermott MM, Liu K, Ferrucci L et al. Decline in functional performance predicts later increased mobility loss and mortality in peripheral arterial disease. J Am Coll Cardiol 2011;57:962-970.

16. The 3C Study Group. Vascular factors and risk of dementia: Design of the Three-City Study and baseline characteristics of the study population. Neuroepidemiology 2003;22:316325.

17. Dumurgier J, Elbaz A, Dufouil C et al. Hypertension and lower walking speed in the elderly: The Three-City Study. J Hypertens 2010;28:1506-1514.

18. Bohannon RW. Comfortable and maximum walking speed of adults aged 20-79 years: Reference values and determinants. Age Ageing 1997;26:15-19.

19. Ko SU, Stenholm S, Metter EJ et al. Age-associated gait patterns and the role of lower extremity strength - results from the Baltimore Longitudinal Study of Aging. Arch Gerontol Geriatr 2012;55:474-479.

20. Rosow I, Breslau N. A Guttman health scale for the aged. J Gerontol 1966;21:556559.

21. Lawton MP, Brody EM. Assessment of older people: Self-maintaining and instrumental activities of daily living. Gerontologist 1969;9:179-186. 
22. Katz S, Ford AB, Moskowitz RW et al. Studies of illness in the aged. The index of ADL: A standardized measure of biological and psychological function. JAMA 1963;185:914-919.

23. Barberger-Gateau P, Rainville C, Letenneur L et al. A hierarchical model of domains of disablement in the elderly: A longitudinal approach. Disabil Rehabil 2000;22:308-317. 24. Peres K, Verret C, Alioum A et al. The disablement process: Factors associated with progression of disability and recovery in French elderly people. Disabil Rehabil 2005;27:263276.

25. Artaud F, Dugravot A, Sabia S et al. Unhealthy behaviours and disability in older adults: Three-City Dijon cohort study. BMJ 2013;347:f4240.

26. Fuhrer R, Rouillon F. La version française de l'échelle CES-D (Center for Epidemiologic Studies-Depression Scale). Description et traduction de l'échelle d'autoévaluation. Psychiatrie Psychobiologie 1989;4:163-166.

27. Blachier M, Dauvilliers Y, Jaussent I et al. Excessive daytime sleepiness and vascular events: The Three City Study. Ann Neurol 2012;71:661-667.

28. Diggle PJ, Sousa I, Chetwynd AG. Joint modelling of repeated measurements and time-to-event outcomes: The fourth Armitage lecture. Stat Med 2008;27:2981-2998.

29. Crowther MJ, Abrams KR, Lambert PC. Joint modelling of longitudinal and survival data. The Stata Journal 2013.

30. Stenholm S, Guralnik JM, Bandinelli S et al. The prognostic value of repeated measures of lower extremity performance: Should we measure more than once? J Gerontol A Biol Sci Med Sci 2014;69:894-899.

31. Lang IA, Llewellyn DJ, Alexander K et al. Obesity, physical function, and mortality in older adults. J Am Geriatr Soc 2008;56:1474-1478.

32. Law CG, Brookmeyer R. Effects of mid-point imputation on the analysis of doubly censored data. Stat Med 1992;11:1569-1578. 
33. Rizopoulos D, Takkenberg JJ. Tools \& techniques—-statistics: Dealing with timevarying covariates in survival analysis_-joint models versus Cox models. EuroIntervention 2014;10:285-288. 
Table 1. Participant Characteristics, Overall and According to Disability Status at the End of Follow-Up

\begin{tabular}{|c|c|c|c|c|}
\hline Characteristic & $\begin{array}{l}\text { Overall, } \\
\mathrm{N}=3,814\end{array}$ & $\begin{array}{l}\text { Not } \\
\text { Disabled, } \\
\mathrm{n}=3,186 \\
(83.5 \%)\end{array}$ & $\begin{array}{l}\text { Disabled, } \\
\mathrm{n}=628 \\
(16.5 \%)^{\mathrm{a}}\end{array}$ & $\begin{array}{l}\text { Odds Ratio } \\
\text { (95\% } \\
\text { Confidence } \\
\text { Interval) }^{b}\end{array}$ \\
\hline \multicolumn{5}{|l|}{ Covariates at study baseline } \\
\hline Age, mean \pm SD & $73.2 \pm 4.6$ & $73.3 \pm 4.7$ & $73.0 \pm 4.0$ & $0.94(0.86-1.02)$ \\
\hline Men, n (\%) & $1,493(39.1)$ & $1,292(40.6)$ & $201(32.0)$ & $0.69(0.58-0.83)$ \\
\hline \multicolumn{5}{|l|}{ Marital status, n (\%) } \\
\hline Married & $2,287(60.0)$ & $1,897(59.5)$ & $390(62.1)$ & $1.87(1.29-2.70)$ \\
\hline Divorced, separated, or widowed & $1,211(31.8)$ & $1,009(31.7)$ & $202(32.2)$ & $1.55(1.06-2.26)$ \\
\hline Single & $316(8.3)$ & $280(8.8)$ & $36(5.7)$ & Ref. \\
\hline \multicolumn{5}{|l|}{ Education, n (\%) } \\
\hline No education or primary school & $1,289(33.8)$ & $1,072(33.6)$ & $217(34.6)$ & $1.04(0.84-1.28)$ \\
\hline Secondary school & $1,235(32.4)$ & $1,026(32.2)$ & $209(33.3)$ & $1.04(0.84-1.29)$ \\
\hline High-school or university degree & $1,290(33.8)$ & $1,088(34.1)$ & $202(32.2)$ & Ref. \\
\hline \multicolumn{5}{|l|}{$\begin{array}{l}\text { Number of unhealthy behaviors, } \mathrm{n} \\
(\%)^{\mathrm{c}}\end{array}$} \\
\hline 0 & $233(6.1)$ & $203(6.4)$ & $30(4.8)$ & Ref. \\
\hline 1 & $958(25.1)$ & $818(25.7)$ & $140(22.3)$ & $1.17(0.76-1.78)$ \\
\hline 2 & $1,563(41.0)$ & $1,301(40.8)$ & $262(41.7)$ & $1.40(0.93-2.11)$ \\
\hline 3 or 4 & $916(24.0)$ & $750(23.5)$ & $166(26.4)$ & $1.57(1.03-2.39)$ \\
\hline Height, cm, mean \pm SD & $161.9 \pm 8.7$ & $162.1 \pm 8.7$ & $160.8 \pm 8.7$ & $0.95(0.84-1.07)$ \\
\hline Fast gait speed, $\mathrm{m} / \mathrm{s}$, mean $\pm \mathrm{SD}$ & $1.54 \pm 0.30$ & $1.55 \pm 0.30$ & $1.49 \pm 0.30$ & $0.84(0.76-0.93)$ \\
\hline \multicolumn{5}{|l|}{ Time-dependent covariates } \\
\hline $\begin{array}{l}\text { Body mass index, } \mathrm{kg} / \mathrm{m}^{2} \\
\text { mean } \pm \mathrm{SD}^{\mathrm{d}}\end{array}$ & $25.8 \pm 3.9$ & $25.7 \pm 3.9$ & $26.2 \pm 4.1$ & $1.17(1.08-1.27)$ \\
\hline $\begin{array}{l}\text { Mini-Mental State Examination } \\
\text { score, mean } \pm \text { SD }^{d}\end{array}$ & $27.4 \pm 1.7$ & $27.4 \pm 1.7$ & $27.4 \pm 1.8$ & $0.96(0.88-1.04)$ \\
\hline 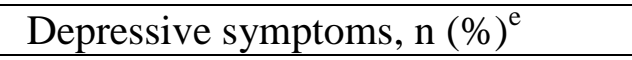 & $1,227(32.2)$ & $968(30.4)$ & $259(41.2)$ & $1.52(1.27-1.82)$ \\
\hline Psychotropic drug use, $\mathrm{n}(\%)^{\mathrm{e}}$ & $1,457(38.2)$ & $1,177(36.9)$ & $280(44.6)$ & $1.30(1.09-1.54)$ \\
\hline Bone fracture, $\mathrm{n}(\%)^{\mathrm{e}}$ & $530(13.9)$ & $424(13.3)$ & $106(16.9)$ & $1.24(0.98-1.57)$ \\
\hline Falls, n $(\%)^{\mathrm{e}}$ & $1,009(26.5)$ & $799(25.1)$ & $210(33.4)$ & $1.44(1.19-1.73)$ \\
\hline Diabetes mellitus, $\mathrm{n}(\%)^{\mathrm{e}}$ & $462(12.1)$ & $369(11.6)$ & $93(14.8)$ & $1.41(1.10-1.81)$ \\
\hline Parkinson's disease, $\mathrm{n}(\%)^{\mathrm{e}}$ & $70(1.8)$ & $50(1.6)$ & $20(3.2)$ & $2.15(1.27-3.64)$ \\
\hline Vision difficulties, $\mathrm{n}(\%)^{\mathrm{e}}$ & $583(15.3)$ & $457(14.3)$ & $126(20.1)$ & $1.45(1.16-1.81)$ \\
\hline Deafness, $\mathrm{n}(\%)^{\mathrm{e}}$ & $631(16.5)$ & $508(15.9)$ & $123(19.6)$ & $1.39(1.11-1.74)$ \\
\hline Dyspnea, $\mathrm{n}(\%)^{\mathrm{e}}$ & $743(19.5)$ & $543(17.0)$ & $200(31.8)$ & $2.23(1.84-2.70)$ \\
\hline $\begin{array}{l}\text { Nonsteroidal antiinflammatory } \\
\text { drugs for joint pain, } \mathrm{n}(\%)^{\mathrm{e}}\end{array}$ & $826(21.7)$ & $663(20.8)$ & $163(26.0)$ & $1.28(1.05-1.56)$ \\
\hline 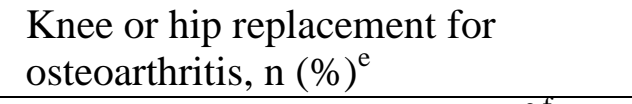 & $337(8.8)$ & $250(7.8)$ & $87(13.9)$ & $1.89(1.46-2.46)$ \\
\hline Cardiovascular disease, $\mathrm{n}(\%)^{\mathrm{e}, \mathrm{f}}$ & $834(21.9)$ & $664(20.8)$ & $170(27.1)$ & $1.55(1.27-1.89)$ \\
\hline Hypertension, $\mathrm{n}(\%)^{\mathrm{e}}$ & $3,301(86.5)$ & $2,741(86.0)$ & $560(89.2)$ & $1.41(1.08-1.86)$ \\
\hline 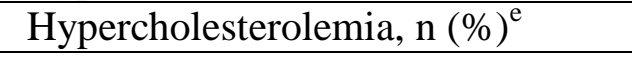 & $1,716(45.0)$ & $1,411(44.3)$ & $305(48.6)$ & $1.18(0.99-1.40)$ \\
\hline
\end{tabular}


${ }^{a}$ Dependent according to the Rosow and instrumental activity of daily living scales with or without the activity of daily living scale (dichotomized hierarchical indicator of disability).

${ }^{b}$ From logistic regression of disability status adjusted for sex; per 1-standard deviation (SD) increase for quantitative covariates.

${ }^{\mathrm{c}}$ The score of unhealthy behaviors was missing for 144 (4\%) participants. An additional "missing" category was included for this variable rather than deleting these subjects.

${ }^{\mathrm{d}}$ Mean of all measures taken during follow-up.

${ }^{\mathrm{e}}$ At least one report over the follow-up.

${ }^{\mathrm{f}}$ Stroke, coronary heart disease, or lower-limb arteritis. 
Table 2. Incidence of Disability in Relation to Fast Gait Speed at Study Baseline and Change in Fast Gait Speed Over Follow-Up: Analyses Based on a Joint Model

\begin{tabular}{|c|c|c|}
\hline Model & $\begin{array}{l}\text { Fast Gait Speed at } \\
\text { Baseline }^{\mathrm{a}}\end{array}$ & $\begin{array}{l}\text { Slope of Change in } \\
\text { Fast Gait Speed }\end{array}$ \\
\hline & \multicolumn{2}{|c|}{ HR (95\% Confidence Interval) \% Change ${ }^{c}$} \\
\hline $0^{\mathrm{d}, \mathrm{e}}$ & $1.73(1.57-1.90)$ & \\
\hline $1^{\mathrm{e}, \mathrm{f}}$ & $1.77(1.60-1.94)$ & $1.38(1.10-1.73)$ \\
\hline $1+$ sociodemographic characteristics $^{\mathrm{g}}$ & $1.81(1.64-2.00)-4.1$ & $1.43(1.14-1.79)-10.9$ \\
\hline $1+$ number of unhealthy behaviors & $1.72(1.56-1.90) 4.6$ & $1.36(1.08-1.71) 4.5$ \\
\hline $1+$ anthropometric characteristics ${ }^{\mathrm{h}}$ & $1.76(1.59-1.94) 0.9$ & $1.37(1.08-1.75) 1.6$ \\
\hline $1+$ cognitive function ${ }^{i}$ & $1.81(1.64-2.00)-4.2$ & $1.45(1.14-1.85)-14.9$ \\
\hline $1+$ depressive symptoms, psychotropic drugs ${ }^{j}$ & $1.77(1.60-1.95)-0.3$ & $1.35(1.05-1.73) 6.9$ \\
\hline $1+$ trauma $^{\mathrm{k}}$ & $1.83(1.66-2.02)-6.4$ & $1.40(1.11-1.77)-4.3$ \\
\hline $1+$ chronic conditions ${ }^{1}$ & $1.66(1.51-1.84) 10.4$ & $1.14(0.90-1.45) 58.9$ \\
\hline $1+$ cardiovascular disease and its risk factors ${ }^{\mathrm{m}}$ & $1.78(1.62-1.97)-1.7$ & $1.37(1.08-1.73) 3.5$ \\
\hline Fully adjusted $^{\mathrm{n}}$ & $1.54(1.39-1.72) 23.6$ & $1.05(0.83-1.32) 86.3$ \\
\hline
\end{tabular}

${ }^{a}$ Per 1-standard deviation (SD) decrease in the random intercept $(0.22 \mathrm{~m} / \mathrm{s})$.

${ }^{\mathrm{b}}$ Per $1-\mathrm{SD}$ decrease in the random slope $(0.013 \mathrm{~m} / \mathrm{s}$ per year $)$.

${ }^{\mathrm{c}}$ Percentage change $\left.=100 \times(\log \text { hazard ratio }(\mathrm{HR}))_{\text {Model } 1} \_\log \mathrm{HR}_{\text {Model }}\right) / \log \mathrm{HR}_{\text {Model } 1}$.

${ }^{\mathrm{d}}$ Model 0 included only the random intercept in the survival submodel.

${ }^{\mathrm{e}}$ Adjusted for sex (reference female) and age at baseline (centered at 65).

${ }^{\mathrm{f}}$ Model 1 included the random intercept and slope in the survival submodel.

${ }^{\mathrm{g}}$ Baseline marital status and education.

${ }^{\mathrm{h}}$ Baseline height and time-dependent body mass index.

${ }^{\mathrm{i}}$ Mini-Mental State Examination score (time-dependent).

${ }^{\mathrm{j}}$ Center for Epidemiologic Studies Depression Scale or use of psychotropic drugs (timedependent).

${ }^{\mathrm{k}}$ Bone fracture, falls (time-dependent).

${ }^{\text {l} D i a b e t e s ~ m e l l i t u s, ~ P a r k i n s o n ' s ~ d i s e a s e, ~ v i s i o n ~ d i f f i c u l t i e s, ~ d e a f n e s s, ~ d y s p n e a, ~ n o n s t e r o i d a l ~}$ antiinflammatory drug use for joint pain, knee or hip replacement for osteoarthritis (timedependent).

${ }^{\mathrm{m}}$ Stroke, coronary heart disease, lower-limb arteritis, hypertension, hypercholesterolemia (time-dependent). 
${ }^{\mathrm{n}}$ All covariates are included in the model. 
Table 3. Incidence of Disability in Relation to Fast Gait Speed at Study Baseline and Change in Fast Gait Speed Over Follow-up: Analyses Based on a Joint Model Excluding the First 4 and 7 Years of Follow-Up

\begin{tabular}{|c|c|c|}
\hline Model & Baseline Fast Gait Speed $^{\mathrm{a}}$ & 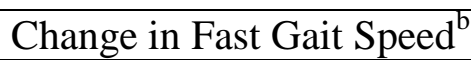 \\
\hline & \multicolumn{2}{|c|}{ HR (95\% Confidence Interval) $\%$ Change $^{c}$} \\
\hline \multicolumn{3}{|l|}{ Exclusion of the first 4 years ${ }^{\mathrm{d}}$} \\
\hline Model $1^{\mathrm{e}}$ & $1.74(1.51-2.01)$ & $1.32(0.98-1.78)$ \\
\hline Fully adjusted model ${ }^{\mathrm{f}}$ & $1.61(1.37-1.89) 14.3$ & $1.04(0.76-1.42) 85.1$ \\
\hline \multicolumn{3}{|l|}{ Exclusion of the first 7 years $^{\mathrm{g}}$} \\
\hline Model $1^{\mathrm{e}}$ & $1.65(1.26-2.17)$ & $1.61(1.04-2.50)$ \\
\hline Fully adjusted model $^{\mathrm{f}}$ & $1.59(1.17-2.17) 7.3$ & $1.30(0.79-2.12) 45.4$ \\
\hline
\end{tabular}

${ }^{a}$ Per 1-standard deviation (SD) decrease in the random intercept $(0.22 \mathrm{~m} / \mathrm{s})$.

${ }^{\mathrm{b}}$ Per 1-SD decrease in the random slope $(0.013 \mathrm{~m} / \mathrm{s}$ per year).

${ }^{c}$ Percentage change $=100 \times\left(\log\right.$ hazard ratio $(\mathrm{HR})$ Model $\left.1 \_\log H R_{\text {Model } \mathrm{i}}\right) / \log \mathrm{HR}_{\text {Model } 1}$.

${ }^{\mathrm{d}}$ Based on 1,849 participants ( $\mathrm{n}=1,112$ women, $\left.60.1 \%\right)$, of whom 272 ( $\mathrm{n}=181$ women, $\left.66.5 \%\right)$ developed disability.

${ }^{\mathrm{e}}$ Adjusted for sex (reference female) and age at baseline (centered at 65).

${ }_{\mathrm{f}}^{\mathrm{f}}$ All covariates included in the model. (See Table 2 for a description of the covariates.)

${ }^{\mathrm{g}}$ Based on 1,211 participants ( $\mathrm{n}=726$ women, $60.0 \%$ ), of whom 77 ( $\mathrm{n}=52$ women, $\left.67.5 \%\right)$ developed disability. 
Figure 1. Predicted trajectories of fast gait speed in disabled (solid line) and not disabled (dashed line) women aged 75 at the end of follow-up. Fast gait speed was modeled using a linear mixed model including a random intercept and slope with a backward time scale.

Estimates from this model are presented in Supplementary Table 3.

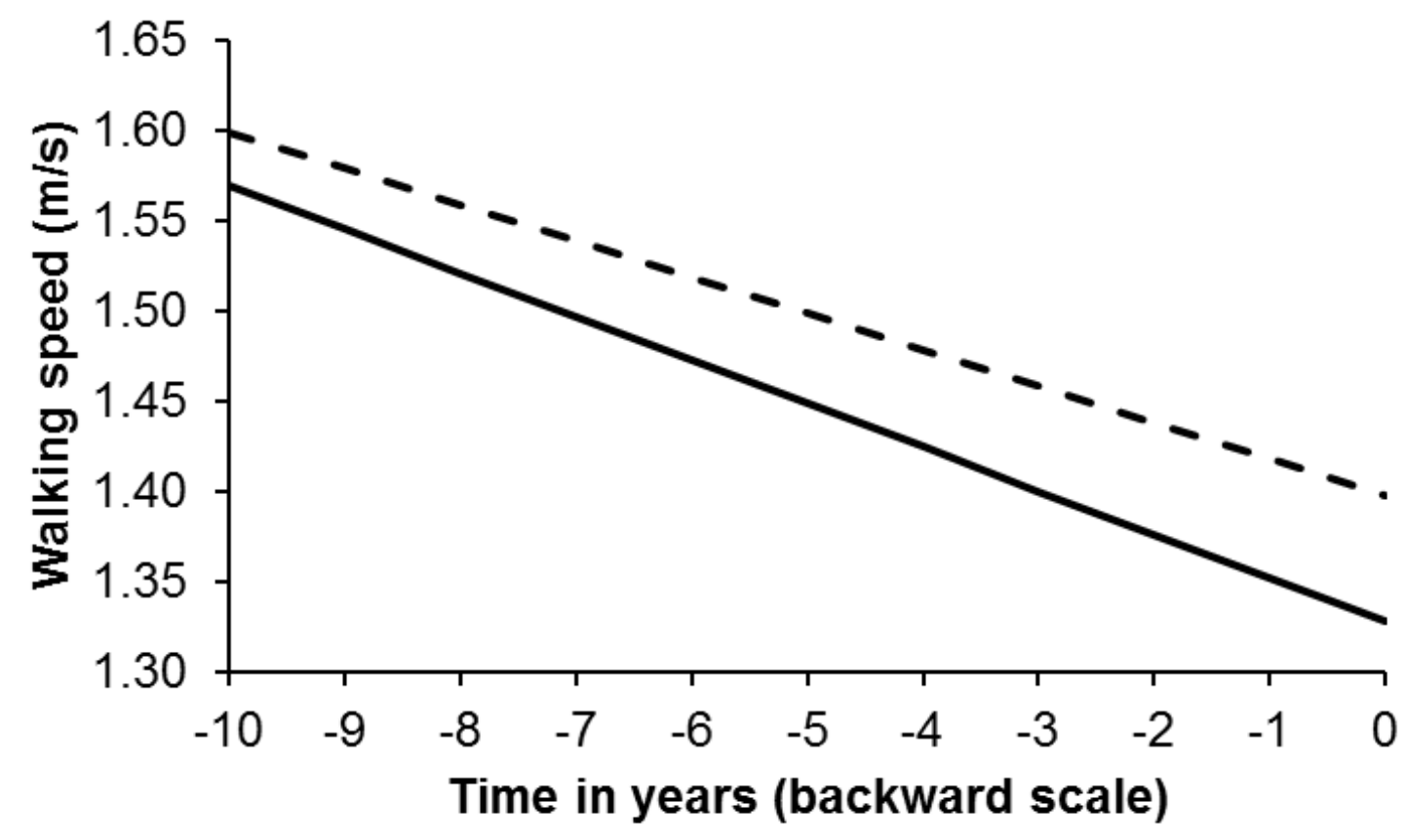




\section{Supplementary methods}

\section{Disability}

\section{Rosow and Breslau scale (mobility)}

\begin{tabular}{lc}
\hline Questions & Score \\
\hline A. Able to do heavy work around the house like washing windows, walls, or floors without & \\
help & \\
Yes & 0 \\
$\quad$ No & 1 \\
B. Able to walk between $500 \mathrm{~m}$ and $1 \mathrm{~km}$ without help & 0 \\
$\quad$ Yes & 1 \\
$\quad$ No & 0 \\
C. Able to walk up and down stairs to the second floor without help & 1 \\
$\quad$ Yes & \\
No &
\end{tabular}

\section{Katz ADL scale}

Questions

Bathing

Bathes self completely

Needs help in bathing only a single part of the body such as the back, genital area or

disabled extremity

Needs help with bathing more than one part of the body, or requires total bathing

Gets clothes from closets and drawers and puts on clothes and outer garments complete

with fasteners

May have help tying shoes

Needs help with dressing self or needs to be completely dressed

Toileting

Goes to toilet, gets on and off, arranges clothes, cleans genital area without help

Needs help transferring to the toilet, cleaning self or uses bedpan or commode

Does not go to the toilet

Transferring

Moves in and out of bed or chair unassisted. Mechanical transferring aides are acceptable $\quad 0$

Needs help in moving from bed to chair or requires a complete transfer 1

Does not leave the bed

Feeding

Gets food from plate into mouth without help 0

Needs help to cut the meal or to butter bread 0

Needs total help with feeding or requires parenteral feeding 1 
Lawton-Brody IADL scale

\begin{tabular}{|c|c|}
\hline Questions & Score \\
\hline \multicolumn{2}{|l|}{ A. Ability to use telephone } \\
\hline 1. Operates telephone on own initiative; looks up and dials numbers, etc. & 0 \\
\hline 2. Dials a few well-known numbers & 0 \\
\hline 3. Answers telephone but does not dial & 0 \\
\hline 4. Does not use telephone at all & 1 \\
\hline \multicolumn{2}{|l|}{ B. Shopping } \\
\hline 1. Takes care of all shopping needs independently & 0 \\
\hline 2. Shops independently for small purchases & 1 \\
\hline 3. Needs to be accompanied on any shopping trip & 1 \\
\hline 4. Completely unable to shop & 1 \\
\hline \multicolumn{2}{|l|}{ C. Mode of Transportation } \\
\hline 1. Travels independently on public transportation or drives own car & 0 \\
\hline 2. Arranges own travel via taxi, but does not otherwise use public transportation & 0 \\
\hline 3. Travels on public transportation when accompanied by another & 0 \\
\hline 4. Travel limited to taxi or automobile with assistance of another & 1 \\
\hline 5. Does not travel at all & 1 \\
\hline \multicolumn{2}{|l|}{ D. Responsibility for own medications } \\
\hline 1. Is responsible for taking medication in correct dosages at correct time & 0 \\
\hline 2. Takes responsibility if medication is prepared in advance in separate dosage & 1 \\
\hline 3. Is not capable of dispensing own medication & 1 \\
\hline \multicolumn{2}{|l|}{ E. Ability to Handle Finances } \\
\hline $\begin{array}{l}\text { 1. Manages financial matters independently (budgets, writes checks, pays rent, bills goes } \\
\text { to bank) }\end{array}$ & 0 \\
\hline 2. Manages day-to-day purchases, but needs help with banking, major purchases, etc. & 0 \\
\hline 3. Incapable of handling money & 1 \\
\hline \multicolumn{2}{|l|}{ For women only } \\
\hline \multicolumn{2}{|l|}{ F. Food Preparation } \\
\hline 1. Plans, prepares and serves adequate meals independently & 0 \\
\hline 2. Prepares adequate meals if supplied with ingredients & 1 \\
\hline 3. Able to heat the dishes already prepared & 1 \\
\hline 4. Needs to have meals prepared and served & 1 \\
\hline \multicolumn{2}{|l|}{ G. Housekeeping } \\
\hline 1. Maintains house alone or with occasional assistance (e.g. "heavy work domestic help") & 0 \\
\hline 2. Performs light daily tasks such as dishwashing, bed making & 0 \\
\hline 3. Performs light daily tasks but cannot maintain acceptable level of cleanliness & 0 \\
\hline 4. Needs help with all home maintenance tasks & 0 \\
\hline 5. Does not participate in any housekeeping tasks & 1 \\
\hline \multicolumn{2}{|l|}{ H. Laundry } \\
\hline 1. Does personal laundry completely & 0 \\
\hline 2. Launders small items; rinses stockings, etc. & 0 \\
\hline 3. All laundry must be done by others & 1 \\
\hline
\end{tabular}




\section{Statistical methods}

\section{Joint model}

We jointly estimated the parameters of a longitudinal and a survival sub-model:

- longitudinal sub-

model:

$W S_{i j}=\beta_{0}+\beta_{1} t_{i j}+\beta_{2} \operatorname{sex}_{i}+\beta_{3} a g e_{i}+\beta_{4} \operatorname{sex}_{i} \times t_{i j}+\beta_{5} a g e_{i} \times t_{i j}+b_{0 i}+b_{1 i} t_{i j}+\varepsilon_{i j}$,

where $\beta$ represents the regression coefficients for fixed effects, $b$ the coefficient for the

random effects, $\varepsilon_{i j}$ denotes measurement error;

- survival sub-model: $h_{i}(t)=h_{0}(t) \exp \left\{\gamma_{1} \operatorname{sex}_{i}+\gamma_{2} a g e_{i}+\alpha_{0} b_{0 i}+\alpha_{1} b_{1 i}\right\}$, where $h_{0}(t)$ is

the baseline hazard function, $\gamma$ the logarithm of the hazard ratio (HR) of disability associated

with covariates, and $\left(\alpha_{0}, \alpha_{1}\right)$ are the parameters of interest here and correspond to the

logarithm of the HR of disability associated with the random intercept and slope respectively (association parameters). We also estimated the HR of disability associated with baseline fast gait speed, through a simpler model that only included the random intercept. 


\section{Supplementary Table 1. Participants' Characteristics and their Association with Fast}

Gait Speed at Study Baseline

\begin{tabular}{|c|c|c|c|c|c|}
\hline \multicolumn{3}{|c|}{ Baseline characteristics } & \multirow{2}{*}{$\begin{array}{c}\text { Overall }^{\mathbf{a}} \\
3532\end{array}$} & \multirow{2}{*}{$\begin{array}{c}\text { Fast gait speed } \\
(\mathbf{m} / \mathbf{s})(\mathrm{SD}) \\
1.54(0.30)\end{array}$} & \multirow[t]{2}{*}{ Beta $(95 \% \text { CI })^{\text {b }}$} \\
\hline $\mathrm{N}(\%)$ & & & & & \\
\hline \multirow[t]{4}{*}{ Age } & \multicolumn{2}{|l|}{$<70$} & $799(22.6)$ & $1.69(0.30)$ & Ref. \\
\hline & \multicolumn{2}{|l|}{$[70-74[$} & $1005(28.5)$ & $1.57(0.29)$ & $-0.10(-0.12,-0.07)$ \\
\hline & \multicolumn{2}{|l|}{$[74-78[$} & $917(26.0)$ & $1.51(0.30)$ & $-0.16(-0.18,-0.13)$ \\
\hline & \multicolumn{2}{|l|}{$\geq 78$} & $811(23.0)$ & $1.42(0.29)$ & $-0.24(-0.27,-0.21)$ \\
\hline \multirow[t]{2}{*}{ Sex } & \multicolumn{2}{|l|}{ Men } & $1376(39.0)$ & $1.69(0.30)$ & $0.23(0.22,0.25)$ \\
\hline & \multicolumn{2}{|l|}{ Women } & $2156(61.0)$ & $1.45(0.27)$ & Ref. \\
\hline \multirow[t]{3}{*}{ Marital status } & \multicolumn{2}{|l|}{ Married } & $2125(60.2)$ & $1.59(0.30)$ & $-0.01(-0.04,0.02)$ \\
\hline & \multicolumn{2}{|c|}{ Divorced, separated, widowed } & $1113(31.5)$ & $1.47(0.29)$ & $-0.02(-0.06,0.01)$ \\
\hline & \multicolumn{2}{|l|}{ Single } & $294(8.3)$ & $1.50(0.31)$ & Ref. \\
\hline \multirow[t]{3}{*}{ Education } & \multicolumn{2}{|c|}{ No education/primary school } & $1184(33.5)$ & $1.46(0.28)$ & $-0.14(-0.16,-0.12)$ \\
\hline & \multicolumn{2}{|c|}{ Secondary school } & $1159(32.8)$ & $1.53(0.30)$ & $-0.08(-0.10,-0.06)$ \\
\hline & \multicolumn{2}{|c|}{ High-school/university } & $1189(33.7)$ & $1.64(0.30)$ & Ref. \\
\hline \multirow[t]{4}{*}{ No of unhealthy behaviours ${ }^{c}$} & \multicolumn{2}{|l|}{0} & $217(6.4)$ & $1.61(0.28)$ & Ref. \\
\hline & \multicolumn{2}{|l|}{1} & $896(26.2)$ & $1.59(0.29)$ & $-0.03(-0.07,0.01)$ \\
\hline & \multicolumn{2}{|l|}{2} & $1457(42.7)$ & $1.52(0.31)$ & $-0.10(-0.13,-0.06)$ \\
\hline & \multicolumn{2}{|l|}{3 or 4} & $845(24.7)$ & $1.51(0.30)$ & $-0.12(-0.16,-0.08)$ \\
\hline \multirow[t]{3}{*}{ BMI $\left(\mathrm{kg} / \mathrm{m}^{2}\right)$} & \multicolumn{2}{|l|}{ Normal } & $1678(47.5)$ & $1.57(0.31)$ & Ref. \\
\hline & \multicolumn{2}{|l|}{ Overweight } & $1383(39.2)$ & $1.54(0.30)$ & $-0.08(-0.09,-0.06)$ \\
\hline & \multicolumn{2}{|l|}{ Obese } & $471(13.3)$ & $1.43(0.29)$ & $-0.18(-0.20,-0.15)$ \\
\hline \multirow[t]{5}{*}{ Height $(\mathrm{cm})$} & Men & Women & & & \\
\hline & $<165$ & $<153$ & $859(24.3)$ & $1.49(0.31)$ & Ref. \\
\hline & {$[165 ; 170[$} & {$[153 ; 157[$} & $842(23.8)$ & $1.51(0.29)$ & $0.02(-0.01,0.04)$ \\
\hline & {$[170 ; 174[$} & {$[157 ; 161[$} & $894(25.3)$ & $1.56(0.30)$ & $0.06(0.03,0.08)$ \\
\hline & $\geq 174$ & $\geq 161$ & $937(26.5)$ & $1.60(0.30)$ & $0.09(0.06,0.11)$ \\
\hline \multirow[t]{3}{*}{ MMSE score } & $<27$ & & $840(23.8)$ & $1.47(0.31)$ & Ref. \\
\hline & {$[27 ; 28[$} & & $613(17.4)$ & $1.52(0.27)$ & $0.03(-0.0004,0.05)$ \\
\hline & $\geq 28$ & & $2079(58.9)$ & $1.58(0.30)$ & $0.08(0.06,0.10)$ \\
\hline Depressive symptoms & Yes & & 767 (21.7) & $1.43(0.28)$ & $-0.09(-0.11,-0.07)$ \\
\hline & No & & $2765(78.3)$ & $1.57(0.30)$ & Ref. \\
\hline
\end{tabular}


Supplementary Table 1 (continued).

\begin{tabular}{|c|c|c|c|c|}
\hline \multicolumn{2}{|l|}{ Baseline characteristics } & \multirow{2}{*}{$\begin{array}{l}\text { Overall }^{\mathrm{a}} \\
848(24.0)\end{array}$} & \multirow{2}{*}{$\begin{array}{c}\text { Fast gait speed } \\
(\mathbf{m} / \mathbf{s})(\mathbf{S D}) \\
1.44(0.29)\end{array}$} & \multirow{2}{*}{$\begin{array}{c}\text { Beta }(95 \% \text { CI })^{\mathbf{b}} \\
-0.08(-0.10,-0.06)\end{array}$} \\
\hline Psychotropic drugs & Yes & & & \\
\hline & No & $2684(76.0)$ & $1.57(0.30)$ & Ref. \\
\hline \multirow[t]{2}{*}{ Bone fracture } & Yes & $232(6.6)$ & $1.46(0.30)$ & $-0.03(-0.06,0.01)$ \\
\hline & No & $3300(93.4)$ & $1.55(0.30)$ & Ref. \\
\hline \multirow[t]{2}{*}{ Falls } & Yes & $204(5.8)$ & $1.40(0.28)$ & $-0.08(-0.12,-0.05)$ \\
\hline & No & $3328(94.2)$ & $1.55(0.30)$ & Ref. \\
\hline \multirow[t]{2}{*}{ Diabetes } & Yes & $263(7.4)$ & $1.52(0.31)$ & $-0.06(-0.10,-0.03)$ \\
\hline & No & $3269(92.6)$ & $1.54(0.30)$ & Ref. \\
\hline \multirow[t]{2}{*}{ Parkinson's disease } & Yes & $33(0.9)$ & $1.49(0.28)$ & $-0.08(-0.16,0.01)$ \\
\hline & No & $3499(99.1)$ & $1.54(0.30)$ & Ref. \\
\hline \multirow[t]{2}{*}{ Vision difficulties } & Yes & $180(5.1)$ & $1.43(0.30)$ & $-0.04(-0.08,-0.004)$ \\
\hline & No & $3352(94.9)$ & $1.55(0.30)$ & Ref. \\
\hline \multirow[t]{2}{*}{ Deafness } & Yes & $290(8.2)$ & $1.51(0.28)$ & $-0.03(-0.07,-0.0003)$ \\
\hline & No & $3242(91.8)$ & $1.54(0.31)$ & Ref. \\
\hline \multirow[t]{2}{*}{ Dyspnea } & Yes & $458(13.0)$ & $1.40(0.28)$ & $-0.12(-0.14,-0.09)$ \\
\hline & No & $3074(87.0)$ & $1.56(0.30)$ & Ref. \\
\hline \multirow[t]{2}{*}{ NSAIDs for joint pain } & Yes & $510(14.4)$ & $1.44(0.30)$ & $-0.08(-0.11,-0.06)$ \\
\hline & No & $3022(85.6)$ & $1.56(0.30)$ & Ref. \\
\hline Knee/hip replacement & Yes & $159(4.5)$ & $1.43(0.28)$ & $-0.10(-0.14,-0.06)$ \\
\hline for osteoarthritis & No & $3373(95.5)$ & $1.55(0.30)$ & Ref. \\
\hline \multirow[t]{2}{*}{ Cardiovascular disease $^{\mathrm{d}}$} & Yes & $552(15.6)$ & $1.50(0.31)$ & $-0.08(-0.11,-0.06)$ \\
\hline & No & $2980(84.4)$ & $1.55(0.30)$ & Ref. \\
\hline \multirow[t]{2}{*}{ Hypertension } & Yes & $2796(79.2)$ & $1.53(0.31)$ & $-0.06(-0.08,-0.04)$ \\
\hline & No & $736(20.8)$ & $1.59(0.29)$ & Ref. \\
\hline \multirow[t]{2}{*}{ Hypercholesterolemia } & Yes & $1196(33.9)$ & $1.52(0.29)$ & $-0.02(-0.04,-0.003)$ \\
\hline & No & $2336(66.1)$ & $1.55(0.31)$ & Ref. \\
\hline \multirow[t]{2}{*}{ Disability at the end of follow-up } & Yes & $575(16.3)$ & $1.49(0.30)$ & $-0.04(-0.07,-0.02)$ \\
\hline & No & $2957(83.7)$ & $1.55(0.30)$ & Ref. \\
\hline
\end{tabular}

${ }^{\mathrm{a}}$ Based on participants with a baseline fast gait speed measure.

${ }^{\mathrm{b}}$ Estimates of the regression coefficient $(95 \% \mathrm{CI})$ from a linear regression of fast gait speed (dependent variable) on covariates, adjusted for age and sex.

${ }^{\mathrm{c}}$ The score of unhealthy behaviors was missing for $144(4 \%)$ participants. We included an additional 'missing' category for this variable rather than deleting these subjects.

${ }^{\mathrm{d}}$ Stroke, coronary heart disease, or lower-limb arteritis. 
Supplementary Table 2. Cross-Tabulation of Sex-Specific Quartiles of the Predicted Intercept (Representing Baseline Fast Gait Speed) and Slope (Representing Change in Fast Gait Speed) of a Non-Adjusted Linear Mixed Model of Fast Gait Speed

\begin{tabular}{|c|c|c|c|c|c|c|c|}
\hline & & & \multicolumn{5}{|c|}{ Quartiles of the predicted intercept of fast gait speed $(\mathrm{m} / \mathrm{s})$} \\
\hline & \multicolumn{2}{|c|}{$\begin{array}{l}\text { Quartiles of the predicted slope of } \\
\text { change in fast gait speed }(\mathrm{m} / \mathrm{s} \text { per year) }\end{array}$} & $\begin{array}{l}\text { Slo } \\
\text { Men } \\
\text { Women }\end{array}$ & $\begin{array}{l}\boldsymbol{r} \\
<1.51 \\
<1.32\end{array}$ & $\begin{array}{l}{[1.51 ; 1.64]} \\
{[1.32 ; 1.47]}\end{array}$ & $\begin{array}{l}{[1.64 ; 1.83]} \\
{[1.47 ; 1.89]}\end{array}$ & $\begin{array}{l}\text { Faster } \\
\geq 1.83 \\
\geq 1.59\end{array}$ \\
\hline \multirow[t]{3}{*}{ Smaller decline } & $\geq-0.016$ & $\geq-0.014$ & $\mathrm{~N}=404$ & $0.6 \%)$ & $\mathrm{N}=149(3.9 \%)$ & $\mathrm{N}=159(4.2 \%)$ & $\mathrm{N}=200(5.2 \%)$ \\
\hline & {$[-0.018 ;-0.016$} & {$[-0.016 ;-0.014[$} & $\mathrm{N}=341$ & $.9 \%)$ & $\mathrm{N}=422(11.1 \%)$ & $\mathrm{N}=141(3.7 \%)$ & $\mathrm{N}=96(2.5 \%)$ \\
\hline & {$[-0.021 ;-0.018$} & {$[-0.019 ;-0.016[$} & $\mathrm{N}=115$ & $.0 \%)$ & $\mathrm{N}=198(5.2 \%)$ & $\mathrm{N}=447(11.7 \%)$ & $\mathrm{N}=188(4.9 \%)$ \\
\hline Greater decline & $<-0.021$ & $<-0.019$ & $\mathrm{~N}=103$ & $2.7 \%)$ & $\mathrm{N}=175(4.6 \%)$ & $\mathrm{N}=207(5.4 \%)$ & $\mathrm{N}=469(12.3 \%)$ \\
\hline
\end{tabular}

Each individual's baseline fast gait speed was estimated as the sum of the fixed effects for the intercept and of the random intercept using best linear unbiased prediction (BLUPs); individual slopes of change in fast gait speed were estimated in a similar way. 
Supplementary Table 3. Linear Mixed Model Estimates of Change in Fast Gait Speed According to Disability Status at the End of the Follow-up

\begin{tabular}{lc}
\hline Characteristics & Estimate $(\mathbf{9 5 \%}$ CI) \\
\hline Intercept $^{\mathrm{a}}$ & $1.398(1.385,1.411)$ \\
Age (centered at 75y) & $-0.010(-0.012,-0.009)$ \\
Sex (men vs. women) & $0.215(0.198,0.232)$ \\
Disability (disabled $v s$. not disabled) & $-0.070(-0.093,-0.048)$ \\
Time & $-0.020(-0.022,-0.019)$ \\
Time $\times$ Sex & $-0.003(-0.005,-0.001)$ \\
Time $\times$ Disability status & $-0.004(-0.007,-0.001)$
\end{tabular}

\footnotetext{
${ }^{\mathrm{a}}$ The intercept corresponds to the mean fast gait speed (m/s) at the end of the follow-up for women not disabled and aged $75 \mathrm{y}$.
} 
Supplementary Table 4. Incidence of Disability in Relation to Fast Gait Speed at Study Baseline and Change in Fast Gait Speed over the Follow-up: Exclusion of 178 Participants who Recovered from Disability and Remained Disability-free during the Follow-up

\begin{tabular}{|c|c|c|c|c|}
\hline \multirow[b]{2}{*}{ Model } & \multicolumn{2}{|c|}{ 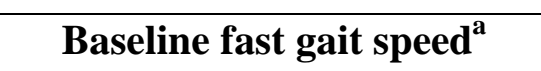 } & \multicolumn{2}{|c|}{ Change in fast gait speed ${ }^{b}$} \\
\hline & HR (95\% CI) & $\%$ change $^{c}$ & HR (95\% CI) & $\%$ change $^{c}$ \\
\hline Model $1^{d}$ & $1.99(1.77,2.24)$ & -- & $1.52(1.16,2.01)$ & -- \\
\hline Fully adjusted model ${ }^{e}$ & $1.72(1.52,1.95)$ & 21.1 & $1.09(0.82,1.43)$ & 80.5 \\
\hline \multicolumn{5}{|c|}{ Analyses are based on 3636 participants (women, $n=2205,60.6 \%$ ), of whom 450 (women, } \\
\hline \multicolumn{5}{|c|}{ a Per one-SD decrease in the random intercept $(0.22 \mathrm{~m} / \mathrm{s})$. } \\
\hline \multicolumn{5}{|c|}{ b Per one-SD decrease in the random slope $(0.013 \mathrm{~m} / \mathrm{s}$ per year $)$. } \\
\hline \multicolumn{5}{|c|}{${ }^{\mathrm{c}}$ Percentage change $=100 \times\left(\log H R_{\text {Model } 1}-\log H R_{\text {Model } i}\right) / \log H R_{\text {Model } 1}$. } \\
\hline${ }^{\mathrm{d}}$ Adjusted for sex (ref & nce, women) and & at baselin & tered et 65 years & \\
\hline
\end{tabular}

